\title{
Trends in Caffeine Use and Association between Clinical Outcomes and Timing of Therapy in Very-Low-Birth-Weight Infants
}

\author{
Nicole R. Dobson, MD ${ }^{\# 1}$, Ravi M. Patel, MD"2, P. Brian Smith, MD, MPH, MHS ${ }^{3}$, Devon R. \\ Kuehn, MD ${ }^{4}$, Jennifer Clark, PhD $^{5}$, Shilpa Vyas-Read, MD $^{2}$, Amy Herring, ScD ${ }^{5}$, Matthew M. \\ Laughon, MD, MPH $^{6}$, David Carlton, MD $^{2}$, and Carl E. Hunt, MD ${ }^{1}$ \\ ${ }^{1}$ Department of Pediatrics, Uniformed Services University of Health Sciences, Bethesda, MD \\ ${ }^{2}$ Emory University School of Medicine and Children's Healthcare of Atlanta, Atlanta, GA \\ ${ }^{3}$ Duke Clinical Research Institute, Durham, NC \\ ${ }^{4}$ Womack Army Medical Center, Fort Bragg, NC \\ ${ }^{5}$ University of North Carolina School of Public Health, Chapel Hill, NC \\ ${ }^{6}$ Department of Pediatrics, University of North Carolina at Chapel Hill, Chapel Hill, NC \\ \# These authors contributed equally to this work.
}

\begin{abstract}
Objective-To examine the effect of early initiation of caffeine therapy on neonatal outcomes and characterized the use of caffeine therapy in very-low-birth-weight (VLBW) infants.

Study design-We analyzed a cohort of 62,056 VLBW infants discharged between 1997 and 2010 who received caffeine. We compared outcomes between infants receiving early caffeine therapy (initial dose $<3$ days of life) and late caffeine therapy (initial dose $\geq 3$ days of life) through propensity scoring using baseline and early clinical variables. The primary outcome was the association between the timing of caffeine initiation and the incidence of bronchopulmonary dysplasia (BPD) or death.
\end{abstract}

Results-We propensity score-matched 29,070 VLBW infants in a 1:1 ratio. Of infants receiving early caffeine therapy, 3681 (27.6\%) died or developed BPD compared with 4591 (34.0\%) infants receiving late caffeine therapy (odds ratio $[\mathrm{OR}]=0.74 ; 99 \%$ confidence interval $0.69-0.80$ ). The incidence of BPD was lower in infants receiving early caffeine (early, 23.1\%; late, 30.7\%; $\mathrm{OR}=0.68 ; 0.63-0.73$ ), and the incidence of death was higher (early, $4.5 \%$; late, $3.7 \%$; $\mathrm{OR}=1.23$;

C 2013 Mosby, Inc. All rights reserved

Corresponding Author: P. Brian Smith, MD, MPH, MHS, Box 17969, DCRI, Durham, NC 27715; phone 919-668-8951; brian.smith@duke.edu..

Publisher's Disclaimer: This is a PDF file of an unedited manuscript that has been accepted for publication. As a service to our customers we are providing this early version of the manuscript. The manuscript will undergo copyediting, typesetting, and review of the resulting proof before it is published in its final citable form. Please note that during the production process errors may be discovered which could affect the content, and all legal disclaimers that apply to the journal pertain.

The authors declare no conflicts of interest. 
1.05-1.43). Infants receiving early caffeine therapy had decreased treatment of a patent ductus arteriosus $(\mathrm{OR}=0.60 ; 0.55-0.65)$ and a shorter duration of mechanical ventilation (mean difference of 6 days; $\mathrm{P}<0.001)$.

Conclusions-Early caffeine initiation is associated with a decreased incidence of BPD. Randomized trials are needed to determine the efficacy and safety of early caffeine prophylaxis in VLBW infants.

\section{Keywords}

methylxanthines; outcomes; bronchopulmonary dysplasia; chronic lung disease; premature infants; neonatal care

Caffeine is one of the most commonly prescribed medications in premature infants. ${ }^{1}$ In the Caffeine for Apnea of Prematurity (CAP) trial published in 2006, infants allocated to receive caffeine had a lower incidence of bronchopulmonary dysplasia (BPD) compared with control infants. ${ }^{2}$ In early follow-up at 18-21 months of age, improved neurodevelopmental outcomes, including a lower incidence of cerebral palsy, were noted in infants allocated to receive caffeine, but these benefits were not as dramatic at 5 years. ${ }^{3,4}$ Approximately half of the early neurodevelopmental improvement of caffeine therapy was explained by improvement in respiratory morbidity, including an approximately 1-week reduction in the duration of mechanical ventilation. ${ }^{2}$ Caffeine may decrease pulmonary morbidity through its beneficial effects on respiratory mechanics ${ }^{5-8}$ and, potentially, by protecting lung tissue against damage from injury. ${ }^{9-11}$ Given the demonstrable benefits of caffeine, understanding its current clinical use is of significant value.

Several aspects of caffeine use are unknown. For example, a post-hoc analysis of the CAP trial suggests that early caffeine therapy (initiation at $<3$ days) is associated with decreased use of endotracheal intubation and positive pressure ventilation when compared with late caffeine therapy ( 33 days). ${ }^{12}$ The risks and benefits of early compared with late initiation of caffeine therapy or the routine use of caffeine prophylaxis have not been evaluated in randomized, controlled trials. In our recent investigation of the association of timing of caffeine therapy and clinical outcomes in a single-center, retrospective study, infants with early initiation of caffeine therapy demonstrated decreased risk of BPD and patent ductus arteriosus (PDA). ${ }^{13}$ In addition, trends in the use of caffeine citrate, approved by the Food and Drug Administration in 1999, ${ }^{14}$ have yet to be studied in a large population of very-lowbirth-weight (VLBW) infants. Caffeine has several advantages over other methylxanthines, including a long half-life and a wide therapeutic window that does not require therapeutic drug monitoring. ${ }^{15}$

We compared the effect of early ( $<3$ days of life) vs. late initiation ( $>3$ days of life) of caffeine therapy on short-term neonatal outcomes, including death and BPD, among others, in a large group of neonatal intensive care units in the United States. We also characterized the use of methylxanthines from 1997 to 2010 . We hypothesize that: 1) early caffeine initiation is associated with improved neonatal outcomes, 2) centers have shifted to earlier initiation of caffeine therapy, and 3) caffeine has replaced the use of aminophylline and theophylline in the current era. 


\section{METHODS}

We used a large, multicenter dataset from the Pediatrix Medical Group. ${ }^{16}$ The use of this dataset has been described previously. ${ }^{1}$ Infants discharged from 1997 to 2010 were eligible for evaluation of the primary and secondary outcomes if they met the following inclusion criteria: (1) receipt of caffeine during hospital course; (2) VLBW (<1500 g birth weight); and (3) admission within 1 day of birth. Exclusion criteria included treatment with multiple methylxanthines and early mortality (death on day of life [DOL] 0-3). In addition, we examined all VLBW infants discharged between 1997 and 2010, including infants not treated with caffeine or treated with other methylxanthines (theophylline and aminophylline), to characterize the trends in the use of methylxanthines.

Postnatal age was characterized using DOL, with the day of birth defined as DOL 0 . We compared patient characteristics and outcomes by timing of initiation of caffeine therapy, with early defined as initiation before DOL 3 and late defined at initiation on or after DOL 3. We determined the type of respiratory support for all infants and the duration of respiratory support for infants requiring mechanical ventilation. Our primary outcome measure was the association between the timing of initiation of caffeine therapy and the incidence of BPD or death. We calculated mortality for all infants who died before hospital discharge. We defined BPD as the need for any respiratory support at a postmenstrual age (PMA) of $360 / 7$ to $366 / 7$ weeks if $<32$ weeks gestational age (GA) at birth or at 28 to 34 postnatal days if $\geq 32$ weeks GA at birth. Infants discharged prior to the BPD evaluation period on room air were defined as having no BPD, and those receiving respiratory support prior to the evaluation period were defined as missing for BPD status. To account for the competing outcomes of mortality and BPD, we used a composite outcome measure of BPD or death. Secondary outcomes were pre-specified and selected based on clinical outcomes that may potentially be affected by caffeine therapy based on results from our previous study ${ }^{13}$ and the CAP trial. ${ }^{2}$ We defined treatment of a PDA as the receipt of either indomethacin or ibuprofen therapy for closure of a PDA after 3 days of postnatal age or surgical ligation. We defined late-onset sepsis as a positive blood culture on or after 3 days of postnatal age. We defined necrotizing enterocolitis (NEC) as the diagnosis of medical or surgical NEC. Additional neonatal co-morbidities were determined by the diagnosis of the corresponding morbidity in the patient's medical record.

\section{Statistical Analyses}

To reduce bias and confounding related to treatment with early caffeine, propensity score (PS) matching was used to obtain similar matched populations of infants receiving early and late caffeine therapy. Matching was chosen over other PS methods, such as stratifying on the quintiles, for ease of interpretation and due to the fact that greater residual imbalance tends to be eliminated by matching. ${ }^{17}$ For the PS model, we used baseline demographic and early clinical variables that could predict early caffeine treatment and/or were predictors of our primary outcome. ${ }^{18}$ The following baseline variables were used in the PS model: GA, birth weight, sex, race, small for GA, Apgar score at 5 minutes, any receipt of antenatal steroids, outborn, center, and birth year. In addition, the following early clinical variables were used: apnea on DOL 0 or 1 , level of respiratory support on DOL 1, maximal fraction of inspired 
oxygen $\left(\mathrm{F}_{\mathrm{i}} \mathrm{O}_{2}\right)$ on DOL 1 , and the use of high-frequency oscillatory ventilation (HFOV) on DOL 1. A greedy match algorithm was used to match infants receiving early and late caffeine therapy. ${ }^{19}$ Subjects were matched without replacement down to a 1-digit match, and any subjects who could not be matched beyond this were excluded.

For unmatched patients, Wald chi-square tests with adjustment for clustering by center were used for categorical variables, and student's t-tests or Wilcoxon rank sum tests were used for continuous variables. For propensity-matched patients, McNemar's test for categorical variables was used for binary categorical variables, Bhakpar's generalized McNemar's test was used for multiple categorical variables, and paired t-tests or Wilcoxon rank sum tests were used for continuous variables. Trends in the use of methylxanthines over time were evaluated using the Spearman rank correlation coefficient. We performed all statistical analysis using SAS 9.2 (Cary, North Carolina). A P $<0.01$ was considered significant.

\section{RESULTS}

Of the 54,707 infants meeting inclusion criteria for study, 29,070 infants (53\%) were PS matched in a 1:1 ratio (Figure 1). PS-matched infants receiving early and late caffeine had similar baseline characteristics with no significant differences in each of the matched variables, including mean birth weight (1055 vs. $1054 \mathrm{~g}, \mathrm{P}=0.77)$ and $\mathrm{GA}(28.1$ vs. 28.0 weeks, $\mathrm{P}=0.70$ ) (Table I).

\section{Early Respiratory Characteristics}

After matching, statistical, but minimal, differences were seen between infants receiving early and late caffeine therapy with use of continuous positive airway pressure (CPAP) therapy ( $22.4 \%$ vs. $21.6 \%$ ), conventional ventilation ( $49.7 \%$ vs. $51.4 \%)$, and HFOV (11.9\% vs. $10.9 \%)$ on DOL $1(\mathrm{P}=0.002)$. In addition, the mean maximal $\mathrm{F}_{\mathrm{i}} \mathrm{O}_{2}$ on DOL 1 was similar between infants receiving early and late caffeine therapy ( 0.27 vs. $0.27 ; \mathrm{P}=0.74)$ (Table I). Infants receiving early caffeine therapy were more likely to be on higher levels of respiratory support, including mechanical ventilation and HFOV, at the initiation of caffeine when compared with infants receiving late caffeine therapy (Table II; available at www.jpeds.com).

\section{Clinical Characteristics}

There was no difference in the incidence of NEC $(\mathrm{P}=0.50)$ between PS-matched groups (Table III). The incidence of central nervous system complications, including any intraventricular hemorrhage (IVH) $(\mathrm{P}<0.001)$, severe (grade 3 or 4$)$ IVH $(\mathrm{P}<0.001)$, and periventricular leukomalacia $(\mathrm{PVL})(\mathrm{P}=0.001)$, was lower in infants receiving early caffeine therapy. In addition, the incidence of retinopathy of prematurity (ROP) was lower in infants receiving early caffeine $(\mathrm{P}<0.001)$, and this included a lower incidence of ROP requiring treatment $(\mathrm{P}<0.001)$. Although uncommon, infants receiving early caffeine also demonstrated a lower incidence of pulmonary interstitial emphysema $(\mathrm{P}<0.001)$.

For infants receiving early caffeine therapy, the mean age at initiation of therapy was DOL 1 (Table III), with the majority of infants initiating caffeine treatment within a day after birth (Figure 2; available at www.jpeds.com). In comparison, infants receiving late caffeine 
therapy had a wide range of age at initiation, with the mean age at initiation of DOL 11. Surfactant use was similar between groups $(\mathrm{P}=0.17)$. In addition, infants receiving early caffeine had a lower use of prophylactic indomethacin $(\mathrm{P}<0.001)$.

\section{Primary Outcome}

For the primary outcome of BPD or death, infants receiving early caffeine had a lower odds of BPD or death (odds ratio [OR] $=0.74 ; 99 \%$ confidence interval [CI] 0.69-0.80) and a lower odds of BPD in survivors (OR=0.68; 0.63-0.73) (Table IV). The risk difference in BPD between infants receiving early and late caffeine was $16.1 \%$ before PS matching and $7.6 \%$ in matched infants. Infants who received early caffeine received less respiratory support at 36 weeks PMA (Table II). The odds of death was higher among infants receiving early caffeine $(\mathrm{OR}=1.23 ; 1.05-1.43)$, with a risk difference of $0.8 \%$ between groups (Table IV).

To determine if the outcomes were specific to infants of a particular GA, we performed a subgroup analysis by GA strata. In subgroup analysis (Table V; available at www.jpeds.com), early caffeine therapy was associated with a consistent effect on the odds of BPD in infants of all GA subgroups. Infants $<24$ weeks gestation who received early caffeine therapy demonstrated an increased odds of death, which was not seen in any of the other GA strata.

\section{Secondary Outcomes}

PDA requiring treatment was less frequent in infants requiring early caffeine therapy (OR=0.60; 0.55-0.65) (Table IV). Mean weight loss was greater during the first week of life (DOL 7) in infants receiving early caffeine therapy (early $-6.3 \mathrm{~g} /$ day; late $-3.5 \mathrm{~g} /$ day; $\mathrm{P}<0.001)$. However, the differences in mean weight gain between groups were no longer present by 28 days of life (early $13.6 \mathrm{~g} /$ day; late $13.7 \mathrm{~g} /$ day; $\mathrm{P}=0.40$ ). Infants receiving early caffeine therapy experienced fewer days on mechanical ventilation (mean difference 6 days, $\mathrm{P}<0.001)$. The odds of late-onset sepsis were also lower among infants receiving early caffeine $(\mathrm{OR}=0.81 ; 0.76-0.88)$.

\section{Trends in Caffeine Use}

The use of caffeine demonstrated a shift towards earlier initiation over time (Figure 3; available at www.jpeds.com). The age at caffeine initiation decreased from a mean of DOL $10\left(5^{\text {th }}, 95^{\text {th }}\right.$ percentile: 0,46$)$ and median of DOL 4 (interquartile range [IQR]: 2,10$)$ in 1997 to a mean of DOL $4\left(5^{\text {th }}, 95^{\text {th }}\right.$ percentile: 0,18$)$ and median of DOL 1 (IQR: 0,3$)$ in 2010. In addition, caffeine progressively replaced aminophylline and theophylline as the methylxanthine of choice, comprising over $90 \%$ of methylxanthine use since 2007 and $96 \%$ of methylxanthine use in 2010 (Figure 4; available at www.jpeds.com). The use of multiple methylxanthines was common before 2001 and decreased substantially to $<5 \%$ of all methylxanthine use after 2007. The percent of VLBW infants exposed to caffeine therapy also demonstrated increases over time, with $43 \%$ of VLBW infants in 1999 receiving caffeine therapy, increasing to $73 \%$ of VLBW infants in 2010 (Figure 5; available at www.jpeds.com). Similar trends were seen for extremely-low-birth-weight infants $(<1000 \mathrm{~g}$ birth weight). 


\section{DISCUSSION}

In VLBW infants, early caffeine initiation was associated with a reduction in neonatal morbidity, including a decreased incidence of BPD and PDA requiring treatment. In addition, centers within this study shifted towards earlier initiation of caffeine therapy over time, with a majority of VLBW infants receiving early caffeine therapy in 2010. Although this observational study limits inferences regarding causality, there is biologic plausibility in how early caffeine therapy may result in improved pulmonary outcomes in the VLBW infant. Caffeine rapidly improves several functions involved in effective respiration, including improvements in pulmonary compliance and airway resistance,, 6 minute ventilation, ${ }^{5}$ and respiratory muscle contractility. ${ }^{7}$ Together, these benefits of caffeine therapy can facilitate earlier weaning from mechanical ventilation or increase the success of initial CPAP therapy and reduce ventilator-associated lung injury. This is particularly relevant in the early neonatal period when the rate of failure of initial CPAP therapy is high and when apnea of prematurity-related symptoms may be prevalent. ${ }^{20}$ The potential benefit of caffeine therapy in reducing ventilator-associated lung injury is supported by findings in our study showing a 6-day reduction in the mean days spent on mechanical ventilation among infants receiving early caffeine therapy.

The association of caffeine therapy with decreased incidence of PDA requiring treatment is also supported by a number of candidate biologic mechanisms, including improvements in cardiac function, ${ }^{21}$ altered fluid balance, ${ }^{22}$ and effects on signaling pathways involved in ductal constriction. ${ }^{23,24}$ Caffeine has been associated with increases in cardiac output and blood pressure in preterm infants ${ }^{21}$ and adults. ${ }^{25}$ In this study, infants receiving early caffeine received less pharmacologic treatment of hypotension. The decreased need for respiratory or cardiac support may reduce the likelihood of a clinician choosing to treat a PDA. In addition, excessive fluid intake in the first week of life is a risk factor for PDA, ${ }^{26}$ and caffeine, through its diuretic properties, ${ }^{22}$ may optimize early fluid balance in VLBW infants. The increased weight loss observed in the first week of life in infants receiving early caffeine therapy may be a result of caffeine's diuretic effects or, alternatively, may be secondary to caffeine's effects on metabolic demands. ${ }^{27}$ However, the indications for treatment of a PDA cannot be ascertained from this database and remain controversial in current neonatal practice. ${ }^{28}$ Interestingly, infants receiving early caffeine therapy had a lower incidence of PDA despite receiving less frequent treatment with prophylactic indomethacin known to decrease the incidence of PDA. ${ }^{29}$ This finding may suggest that centers (or clinicians) that used indomethacin prophylaxis were less likely to initiate early caffeine therapy.

Although not selected as pre-specified outcome measures, decreased incidences of IVH and ROP were seen in infants receiving early caffeine therapy. We speculate that the decreased ROP seen in infants treated with early caffeine is a consequence of improved pulmonary morbidity and a decreased need for ventilation and exposure to supplemental oxygen. Severe ROP is also associated with intermittent hypoxia, which may be reduced by caffeine treatment. ${ }^{30}$ In the CAP trial, infants allocated to receive caffeine had a lower incidence of severe ROP. The association of early caffeine therapy and decreased IVH, including severe IVH, requires additional study. One candidate mechanism for this finding is caffeine's effect 
on decreasing cerebral blood flow, ${ }^{31,32}$ which, potentially, may better protect the germinal matrix from hemorrhage.

In this multicenter cohort, the indication for early caffeine therapy is likely to have varied among centers. Interestingly, although apnea symptoms are often inconsistently reported and documented, the incidence of early apnea was infrequent, implying that perhaps apnea was not a common indication for early initiation of caffeine treatment. In addition, over $60 \%$ of infants in the early caffeine group received mechanical ventilation on DOL 1 . Therefore, we speculate that infants receiving early caffeine therapy were treated prophylactically to prevent apnea or were treated to facilitate weaning from the ventilator.

Although not an accepted indication for caffeine use, we cannot exclude the possibility that some centers in this study may have also used early caffeine therapy for the prevention of BPD. ${ }^{33}$ We attempted to account for confounding variables related to the indication for early initiation of caffeine therapy by robustly controlling for factors that would potentially influence early therapy, including baseline and early respiratory support characteristics, through the use of PS matching. The association of early caffeine therapy and decreased BPD remained significant in PS-matched infants who had a similar GA, birth weight, sex, race, respiratory support, and maximal $\mathrm{F}_{\mathrm{i}} \mathrm{O}_{2}$ on DOL 1. Importantly, these 6 variables are the primary predictors of the risk of BPD. ${ }^{34}$ The similarity in each of these variables between groups reassured us that PS-matched infants receiving late caffeine did not represent a population with a markedly increased or decreased baseline risk of BPD. In addition, several of these variables are primary determinants of neonatal mortality and longterm neurologic outcome. ${ }^{35}$

Infants receiving early caffeine, particularly those $<24$ weeks gestation, had a higher incidence of death. Although this finding is of potential concern, the lower mortality observed in the late caffeine cohort may be due to a survival bias. Mortality at this gestation is high, and most deaths occur early in the infant's course. For example, an infant who received early caffeine (DOL 0-2) was at risk of dying on DOL 4. An infant included in the late caffeine cohort who received caffeine on DOL 5 could not have died on DOL 4. Additional study is needed to confirm this finding in infants born at the earliest gestations.

Our study has several limitations. Changes in clinical practice over the period of this study may have influenced the clinical outcomes. Recent data suggest a small decrease in the incidence of BPD over the last decade without any apparent decreases in mortality. ${ }^{36,37}$ To account for these potential temporal changes in outcomes, we included birth year in our PSmatching model. Another limitation was our inability to use a physiologic definition of BPD, which may be a more reliable measure of BPD in VLBW infants. ${ }^{38}$ Due to limitations in the data available to us, we were unable to capture all variables that may have influenced the indication for caffeine initiation or clinical outcomes. These include maternal variables such as chorioamnionitis and therapies such as postnatal steroid use for the treatment of severe lung disease. Additionally, the differences in hypotension requiring treatment, and potentially influenced by caffeine's effects on cardiac function, ${ }^{21}$ may equally have been reflective of an increased severity of illness in infants receiving late caffeine therapy. The association between early caffeine initiation and reduction in a number of neonatal 
morbidities may have been affected by treatment and selection bias. Despite our attempts to address confounding factors, we were unable to account for all factors that may have influenced early caffeine therapy or were reflective of early severity of illness. In addition, it is important to note that the reduced sample size in the subgroup analyses may have limited our ability to detect clinically significant differences.

Our findings have important clinical and research implications for VLBW infants. This study demonstrates that caffeine is now widely used in premature infants, with approximately $70 \%$ of all VLBW infants receiving therapy in 2008-2010. In addition, a limited number of currently available therapies exist to decrease the burden of BPD and PDA. The findings in this study are in line with observations from our previous singlecenter, retrospective study where early caffeine therapy was also associated with a decreased incidence of BPD or death. ${ }^{13}$ To our knowledge, these are the only studies to report an association between early caffeine therapy and a reduction in BPD and PDA requiring treatment.

Caffeine is already a widely used medication in VLBW infants, but optimizing caffeine therapy to maximize treatment effect may yield substantial benefits for VLBW infants at risk for BPD and PDA. Potentially, other benefits of early caffeine prophylaxis may include a reduction in ROP and IVH. A change in practice towards earlier caffeine therapy is already occurring, but randomized controlled trials are needed to investigate the benefit and safety of early caffeine prophylaxis and its effect on short- and long-term outcomes.

\section{Acknowledgments}

We would like to acknowledge Sofia Aliaga and Bradley Yoder for their input on data interpretation and manuscript development.

Supported by the National Center for Advancing Translational Sciences of the National Institutes of Health (UL1TR000454 and KL2TR000455 to R.P.) and the Eunice Kennedy Shriver National Institutes of Child Health and Human Development (1K23HD060040-01), the American Recovery and Reinvestment Act (1R18AE000028-01 to P.S.), and the National Center for Advancing Translational Sciences of the National Institutes of Health (NIH; UL1TR001117). The views expressed in this article are those of the authors and do not necessarily reflect the official policy or position of the Department of the Army, Department of Defense, the U.S. government, or NIH.

\section{ABBREVIATIONS}

$\begin{array}{ll}\text { BPD } & \text { Bronchopulmonary dysplasia } \\ \text { CAP } & \text { Caffeine for Apnea of Prematurity } \\ \text { CI } & \text { Confidence interval } \\ \text { CPAP } & \text { Continuous positive airway pressure } \\ \text { DOL } & \text { Day of life } \\ \text { GA } & \text { Gestational age } \\ \text { FiO } 2 & \text { Fraction of inspired oxygen } \\ \text { HFOV } & \text { High-frequency oscillatory ventilation }\end{array}$




$\begin{array}{ll}\text { IQR } & \text { Interquartile range } \\ \text { IVH } & \text { Intraventricular hemorrhage } \\ \text { NEC } & \text { Necrotizing enterocolitis } \\ \text { OR } & \text { Odds ratio } \\ \text { PDA } & \text { Patent ductus arteriosus } \\ \text { PMA } & \text { Postmenstrual age } \\ \text { PS } & \text { Propensity score } \\ \text { PVL } & \text { Periventricular leukomalacia } \\ \text { ROP } & \text { Retinopathy of prematurity } \\ \text { VLBW } & \text { Very low birth weight }\end{array}$

\section{REFERENCES}

1. Clark RH, Bloom BT, Spitzer AR, Gerstmann DR. Reported medication use in the neonatal intensive care unit: data from a large national data set. Pediatrics. 2006; 117:1979-87. [PubMed: 16740839]

2. Schmidt B, Roberts RS, Davis P, Doyle LW, Barrington KJ, Ohlsson A, et al. Caffeine therapy for apnea of prematurity. N Engl J Med. 2006; 354:2112-21. [PubMed: 16707748]

3. Schmidt B, Anderson PJ, Doyle LW, Dewey D, Grunau RE, Asztalos EV, et al. Survival without disability to age 5 years after neonatal caffeine therapy for apnea of prematurity. JAMA. 2012; 307:275-82. [PubMed: 22253394]

4. Schmidt B, Roberts RS, Davis P, Doyle LW, Barrington KJ, Ohlsson A, et al. Long-term effects of caffeine therapy for apnea of prematurity. N Engl J Med. 2007; 357:1893-1902. [PubMed: 17989382]

5. Aranda JV, Turmen T, Davis J, Trippenbach T, Grondin D, Zinman R, et al. Effect of caffeine on control of breathing in infantile apnea. J Pediatr. 1983; 103:975-8. [PubMed: 6644439]

6. Davis JM, Bhutani VK, Stefano JL, Fox WW, Spitzer AR. Changes in pulmonary mechanics following caffeine administration in infants with bronchopulmonary dysplasia. Pediatr Pulmonol. 1989; 6:49-52. [PubMed: 2704583]

7. Supinski GS, Deal EC Jr, Kelsen SG. The effects of caffeine and theophylline on diaphragm contractility. Am Rev Respir Dis. 1984; 130:429-33. [PubMed: 6476593]

8. Yoder B, Thomson M, Coalson J. Lung function in immature baboons with respiratory distress syndrome receiving early caffeine therapy: a pilot study. Acta Paediatr. 2005; 94:92-8. [PubMed: 15858967]

9. Weichelt U, Cay R, Schmitz T, Strauss E, Sifringer M, Bührer C, et al. Prevention of hyperoxiamediated pulmonary inflammation in neonatal rats by caffeine. Eur Respir J. 2013; 41:966-73. [PubMed: 22878872]

10. Li J, Li G, Hu JL, Fu XH, Zeng YJ, Zhou YG, et al. Chronic or high dose acute caffeine treatment protects mice against oleic acid-induced acute lung injury via an adenosine A2A receptorindependent mechanism. Eur J Pharmacol. 2011; 654:295-303. [PubMed: 21238452]

11. Oliveira-Junior IS, Pinheiro BV, Silva ID, Salomao R, Zollner RL, Beppu OS. Pentoxifylline decreases tumor necrosis factor and interleukin-1 during high tidal volume. Braz J Med Biol Res. 2003; 36:1349-57. [PubMed: 14502367]

12. Davis PG, Schmidt B, Roberts RS, Doyle LW, Asztalos E, Haslam R, et al. Caffeine for Apnea of Prematurity trial: benefits may vary in subgroups. J Pediatr. 2010; 156:382-7. [PubMed: 19926098] 
13. Patel RM, Leong T, Carlton DP, Vyas-Read S. Early caffeine therapy and clinical outcomes in extremely preterm infants. J Perinatol. 2013; 33:134-40. [PubMed: 22538326]

14. Bhatia J. Current options in the management of apnea of prematurity. Clin Pediatr (Phila). 2000; 39:327-36. [PubMed: 10879934]

15. Henderson-Smart DJ, De Paoli AG. Methylxanthine treatment for apnoea in preterm infants. Cochrane Database Syst Rev. 2010:CD000140. [PubMed: 21154343]

16. Spitzer AR, Ellsbury DL, Handler D, Clark RH. The Pediatrix BabySteps Data Warehouse and the Pediatrix QualitySteps improvement project system — tools for "meaningful use" in continuous quality improvement. Clin Perinatol. 2010; 37:49-70. [PubMed: 20363447]

17. Austin PC. A tutorial and case study in propensity score analysis: an application to estimating the effect of in-hospital smoking cessation counseling on mortality. Multivariate Behav Res. 2011; 46:119-51. [PubMed: 22287812]

18. Brookhart MA, Schneeweiss S, Rothman KJ, Glynn RJ, Avorn J, Sturmer T. Variable selection for propensity score models. Am J Epidemiol. 2006; 163:1149-56. [PubMed: 16624967]

19. Parsons, LS. [Accessed January 17, 2013] Reducing bias in a propensity score matched-pair sample using greedy matching techniques. Available at: http://www2.sas.com/proceedings/sugi26/ p214-26.pdf.

20. Finer NN, Carlo WA, Walsh MC, Rich W, Gantz MG, Laptook AR, et al. Early CPAP versus surfactant in extremely preterm infants. N Engl J Med. 2010; 362:1970-9. [PubMed: 20472939]

21. Soloveychik V, Bin-Nun A, Ionchev A, Sriram S, Meadow W. Acute hemodynamic effects of caffeine administration in premature infants. J Perinatol. 2009; 29:205-8. [PubMed: 19052555]

22. Gillot I, Gouyon JB, Guignard JP. Renal effects of caffeine in preterm infants. Biol Neonate. 1990; 58:133-6. [PubMed: 2279048]

23. Blaustein MP, Golovina VA, Song H, Choate J, Lencesova L, Robinson SW, et al. Organization of $\mathrm{Ca} 2+$ stores in vascular smooth muscle: functional implications. Novartis Found Symp. 2002; 246:125-37. discussion 137-41, 221-7. [PubMed: 12164305]

24. Whorton AR, Collawn JB, Montgomery ME, Young SL, Kent RS. Arachidonic acid metabolism in cultured aortic endothelial cells. Effect of cAMP and 3-isobutyl-1-methylxanthine. Biochem Pharmacol. 1985; 34:119-23. [PubMed: 2578280]

25. Hartley TR, Lovallo WR, Whitsett TL. Cardiovascular effects of caffeine in men and women. Am J Cardiol. 2004; 93:1022-6. [PubMed: 15081447]

26. Stephens BE, Gargus RA, Walden RV, Mance M, Nye J, McKinley L, et al. Fluid regimens in the first week of life may increase risk of patent ductus arteriosus in extremely low birth weight infants. J Perinatol. 2008; 28:123-8. [PubMed: 18046337]

27. Bauer J, Maier K, Linderkamp O, Hentschel R. Effect of caffeine on oxygen consumption and metabolic rate in very low birth weight infants with idiopathic apnea. Pediatrics. 2001; 107:660-3. [PubMed: 11335740]

28. Hamrick SE, Hansmann G. Patent ductus arteriosus of the preterm infant. Pediatrics. 2010; 125:1020-30. [PubMed: 20421261]

29. Schmidt B, Davis P, Moddemann D, Ohlsson A, Roberts RS, Saigal S, et al. Long-term effects of indomethacin prophylaxis in extremely-low-birth-weight infants. N Engl J Med. 2001; 344:196672. [PubMed: 11430325]

30. Di Fiore JM, Kaffashi F, Loparo K, Sattar A, Schluchter M, Foglyano R, et al. The relationship between patterns of intermittent hypoxia and retinopathy of prematurity in preterm infants. Pediatr Res. 2012; 72:606-12. [PubMed: 23037873]

31. Hoecker C, Nelle M, Poeschl J, Beedgen B, Linderkamp O. Caffeine impairs cerebral and intestinal blood flow velocity in preterm infants. Pediatrics. 2002; 109:784-7. [PubMed: 11986437]

32. Tracy MB, Klimek J, Hinder M, Ponnampalam G, Tracy SK. Does caffeine impair cerebral oxygenation and blood flow velocity in preterm infants? Acta Paediatr. 2010; 99:1319-23. [PubMed: 20412101]

33. Schmidt B, Roberts R, Millar D, Kirpalani H. Evidence-based neonatal drug therapy for prevention of bronchopulmonary dysplasia in very-low-birth-weight infants. Neonatology. 2008; 93:284-7. [PubMed: 18525211] 
34. Laughon MM, Langer JC, Bose CL, Smith PB, Ambalavanan N, Kennedy KA, et al. Prediction of bronchopulmonary dysplasia by postnatal age in extremely premature infants. Am J Respir Crit Care Med. 2011; 183:1715-22. [PubMed: 21471086]

35. Tyson JE, Parikh NA, Langer J, Green C, Higgins RD. Intensive care for extreme prematuritymoving beyond gestational age. N Engl J Med. 2008; 358:1672-81. [PubMed: 18420500]

36. Fanaroff AA, Stoll BJ, Wright LL, Carlo WA, Ehrenkranz RA, Stark AR, et al. Trends in neonatal morbidity and mortality for very low birthweight infants. Am J Obstet Gynecol. 2007; 196:147.e1-8. [PubMed: 17306659]

37. Ruegger C, Hegglin M, Adams M, Bucher HU. Population based trends in mortality, morbidity and treatment for very preterm- and very low birth weight infants over 12 years. BMC Pediatrics. 2012; 12:17. [PubMed: 22356724]

38. Walsh MC, Wilson-Costello D, Zadell A, Newman N, Fanaroff A. Safety, reliability, and validity of a physiologic definition of bronchopulmonary dysplasia. J Perinatol. 2003; 23:451-6. [PubMed: 13679930] 

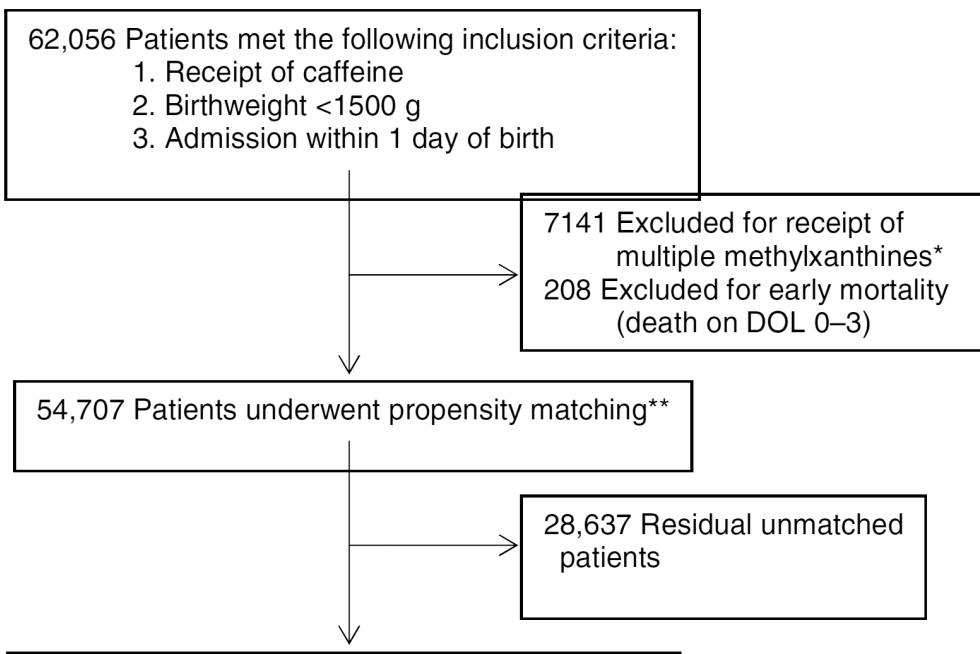

29,070 Patients propensity matched in a 1:1 ratio

Figure 1.

After propensity matching, 29,070 patients (53\%) meeting inclusion criteria were eligible for analysis of the primary and secondary outcomes. *Patients receiving multiple methylxanthines included in the evaluation of trends in methylxanthine use over time. **Select comparisons of full cohort meeting inclusion and exclusion criteria, including unmatched patients, were performed. Abbreviations: DOL, day of life; 


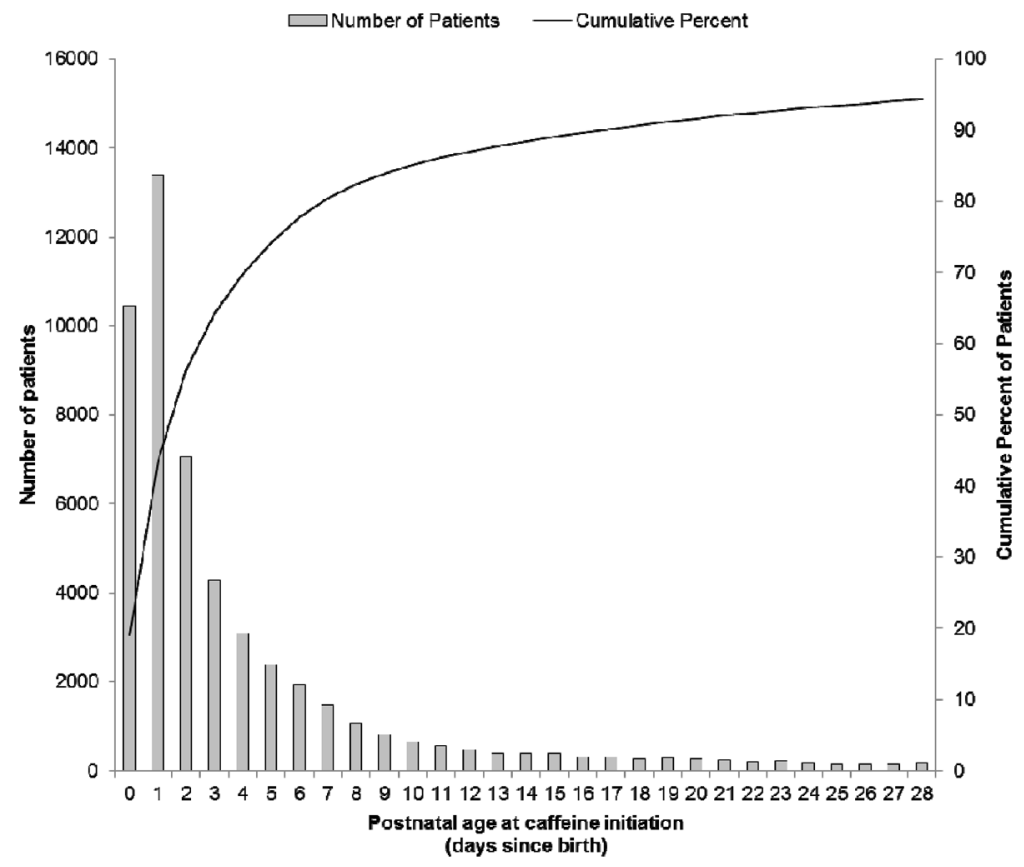

Figure 2.

(online). Histogram demonstrates distribution in the number of infants receiving caffeine therapy by postnatal age at initiation. Data presented for a total of 51,623 unmatched infants $<1500 \mathrm{~g}$ at birth who received caffeine therapy. Infants with caffeine initiation beyond 28 days since birth, comprising $5.6 \%$ of patients, not depicted $(\mathrm{N}=3084)$. 

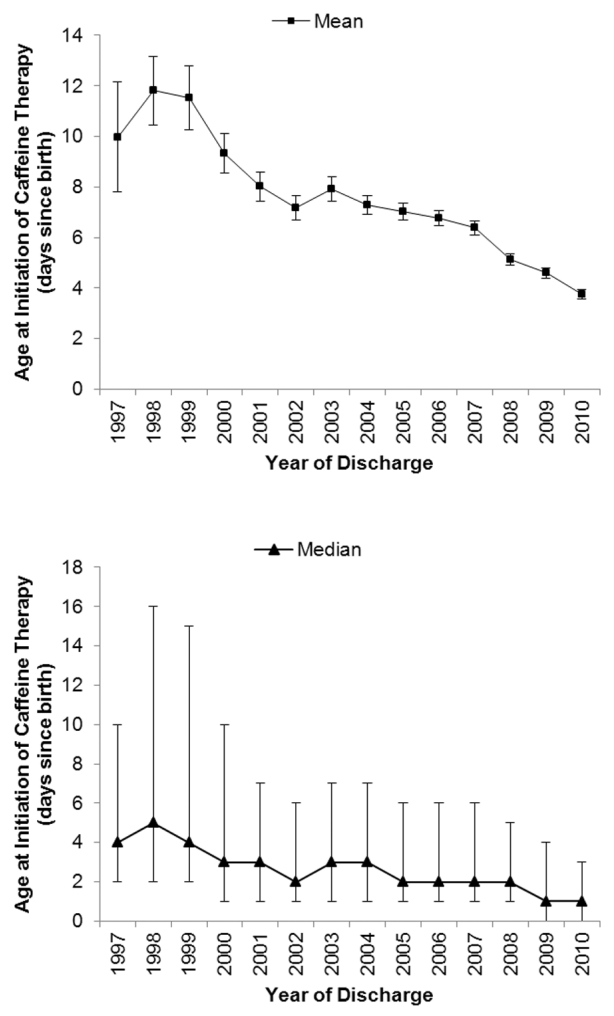

Figure 3.

(online). The mean and median postnatal age at caffeine initiation in very-low-birth-weight infants demonstrates a trend towards early caffeine therapy over time. $\mathrm{R}^{2}=0.89$ for negative correlation between birth year and mean age at caffeine initiation. Whisker bars indicate 95\% confidence intervals for mean values and interquartile range for median values. 

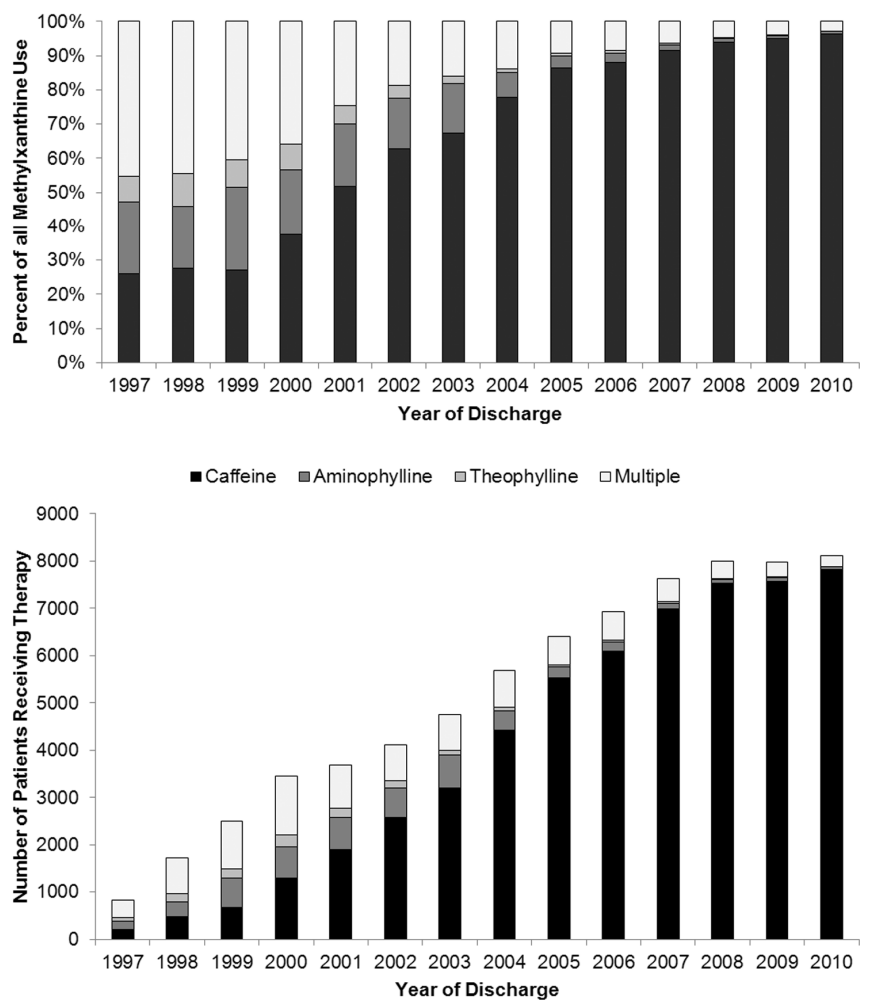

Figure 4.

(online). The percent of very-low-birth-weight (VLBW) infants receiving methylxanthine therapy as a fraction of overall methylxanthine use (top panel) and number of VLBW infants receiving methylxanthines (bottom panel) are displayed. Exclusive use of caffeine increased from $26 \%$ in 1997 to $96 \%$ in 2010. Treatment with methylxanthines other than caffeine, including multiple methylxanthines, predominated prior to 2001, and infrequent after 2007 $(<5 \%)$. 


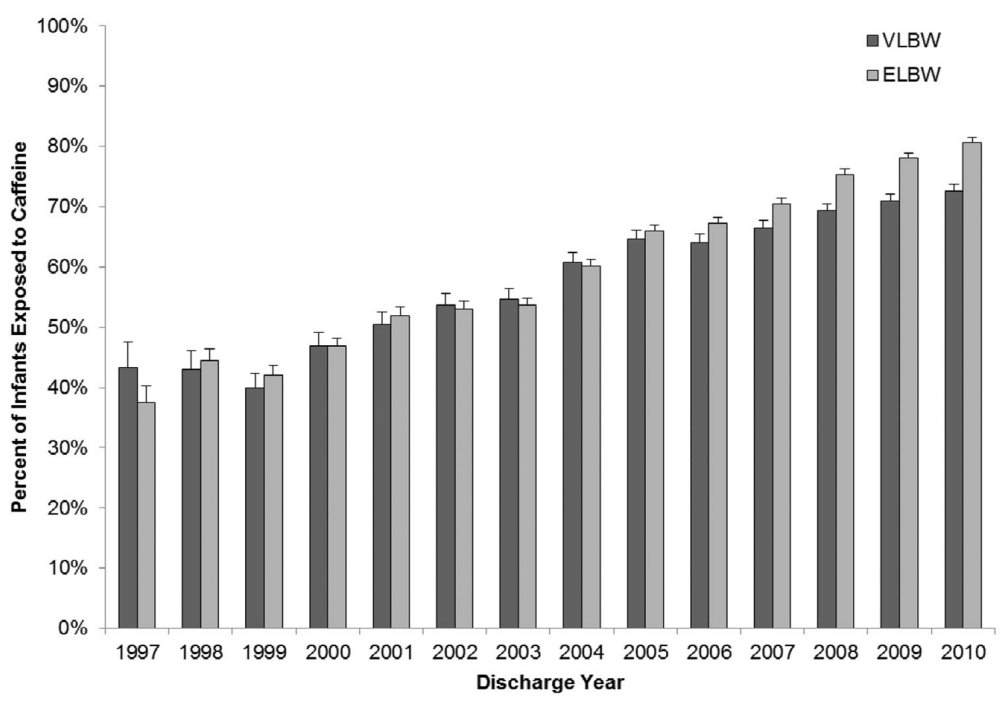

Figure 5.

(online). Graph denotes the percent of very-low-birth-weight (VLBW) and extremely-lowbirth-weight (ELBW) infants exposed to caffeine during hospitalization. Whisker bars indicate $95 \%$ confidence intervals. 


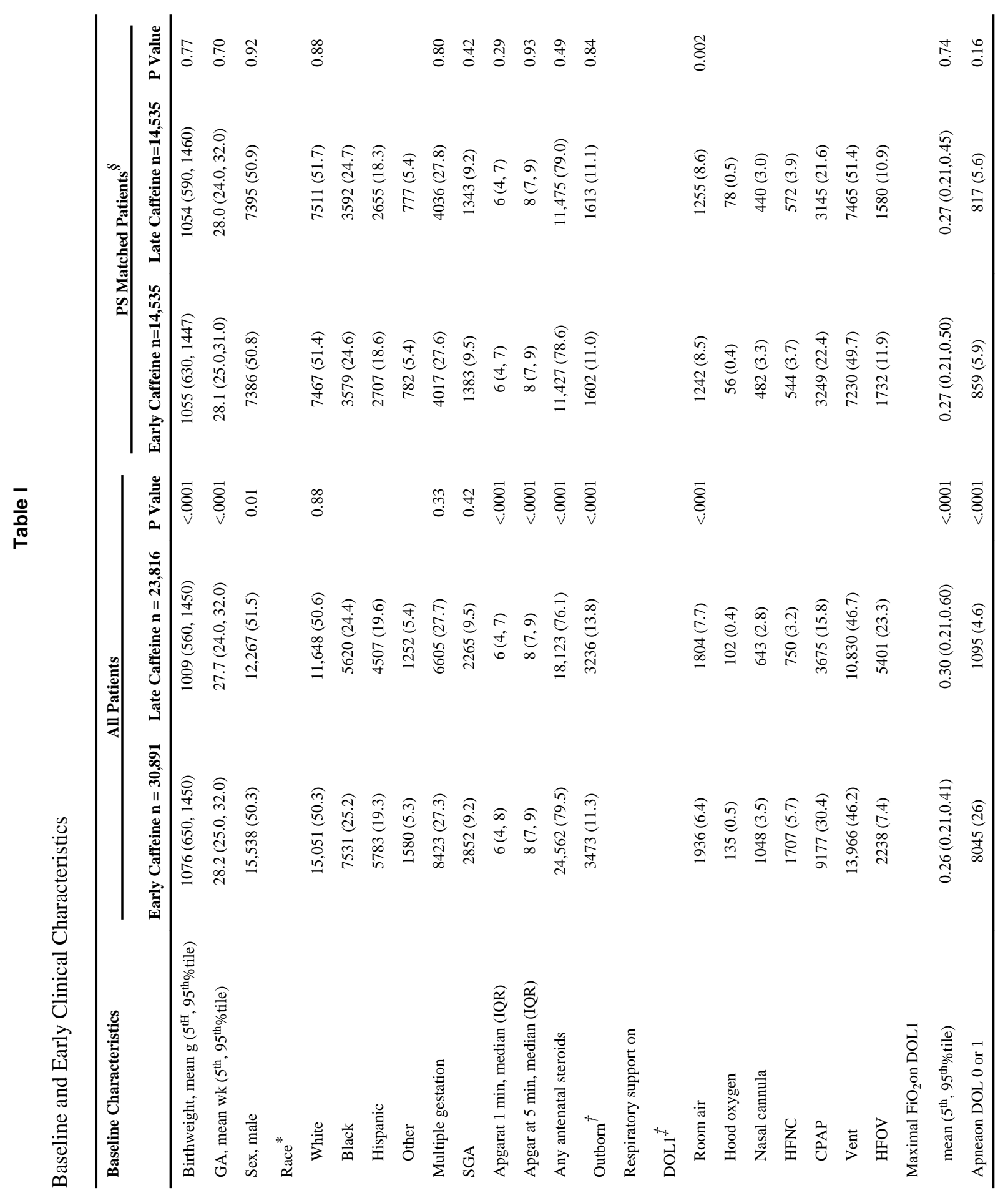




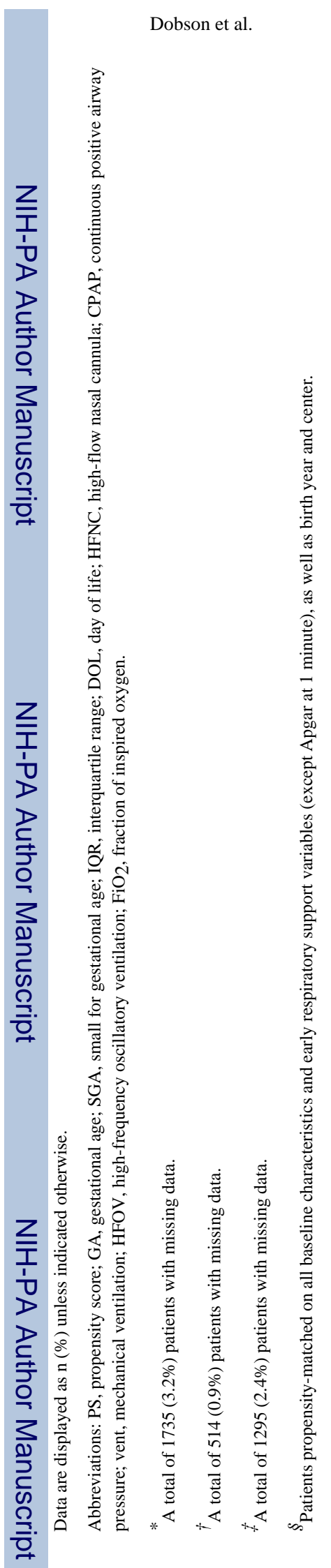

Page 18

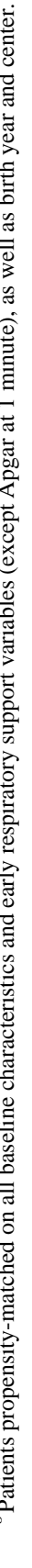




\section{Table II}

\section{Respiratory Support Characteristics (Online)}

\begin{tabular}{|c|c|c|c|}
\hline \multirow[t]{2}{*}{ Respiratory Characteristics at Caffeine Initiation } & \multicolumn{3}{|c|}{ PS Matched Patients } \\
\hline & Early Caffeine $n=14,523$ & Late Caffeine $n=14,498$ & $\mathbf{P}$ \\
\hline \multicolumn{4}{|l|}{ Respiratory support at caffeine initiation ${ }^{*}$} \\
\hline Room air & $1116(7.7)$ & $2624(18.1)$ & $<0.0001$ \\
\hline Hood oxygen & $86(0.6)$ & $51(0.4)$ & \\
\hline Nasal cannula & $509(3.5)$ & 1635 (11.3) & \\
\hline HFNC & $609(4.2)$ & $1118(7.7)$ & \\
\hline CPAP & $3131(21.6)$ & 2545 (17.6) & \\
\hline Vent & $7562(52.1)$ & $5678(39.2)$ & \\
\hline HFOV & $1510(10.4)$ & $847(5.8)$ & \\
\hline \multicolumn{4}{|l|}{ Maximal $\mathrm{FiO}_{2}$ at caffeine initiation } \\
\hline mean $\left(5^{\text {th }}, 95^{\text {th }} \%\right.$ tile $)$ & $0.28(0.21,0.50)$ & $0.28(0.21,0.50)$ & 0.97 \\
\hline median (IQR) & $0.21(0.21,0.30)$ & $0.22(0.21,0.30)$ & \\
\hline \multicolumn{4}{|l|}{$\underline{\text { Respiratory Characteristics at } 36 \text { 0/7 weeks } \mathrm{PMA}^{\dagger}}$} \\
\hline Infants evaluated at $360 / 7$ weeks PMA & 8879 & 9813 & \\
\hline \multicolumn{4}{|l|}{ Respiratory support at 36 0/7 weeks PMA } \\
\hline Room air & 4949 (55.7) & $4713(48.0)$ & $<0.0001$ \\
\hline Hood oxygen & $68(0.8)$ & $163(1.0)$ & \\
\hline Nasal cannula & $2439(27.5)$ & $3081(31.4)$ & \\
\hline HFNC & $482(5.4)$ & $656(6.7)$ & \\
\hline CPAP & $522(5.9)$ & $639(6.5)$ & \\
\hline Vent & $375(4.2)$ & $565(5.8)$ & \\
\hline HFOV & $44(0.5)$ & $64(0.7)$ & \\
\hline Receipt of $\mathrm{FiO}_{2}>0.21$ & $3064(34.8)$ & $4150(42.7)$ & $<0.0001$ \\
\hline Receipt of $\mathrm{FiO}_{2}>0.30$ & $1972(22.4)$ & $2653(27.3)$ & $<0.0001$ \\
\hline
\end{tabular}

Data are displayed as $\mathrm{n}(\%)$ unless indicated otherwise.

Abbreviations: PS, propensity score; HFNC, high flow nasal cannula; CPAP, continuous positive airway pressure; vent, mechanical ventilation; $\mathrm{HFOV}$, high-frequency oscillatory ventilation; IQR, interquartile range; PMA, postmenstrual age; FiO2, fraction of inspired oxygen.

A total of $49(0.2 \%)$ PS-matched patients with missing data.

${ }^{\dagger}$ For the early caffeine group, 659 (4.5\%) infants died before discharge, 4439 (30.5\%) infants evaluated before 36 weeks PMA, and 558 (3.8\%) had missing data. For the late caffeine group, 542 (3.7\%) infants died before discharge, 3707 (25.5\%) of infants evaluated before 36 weeks PMA, and $473(3.3 \%)$ had missing data. 


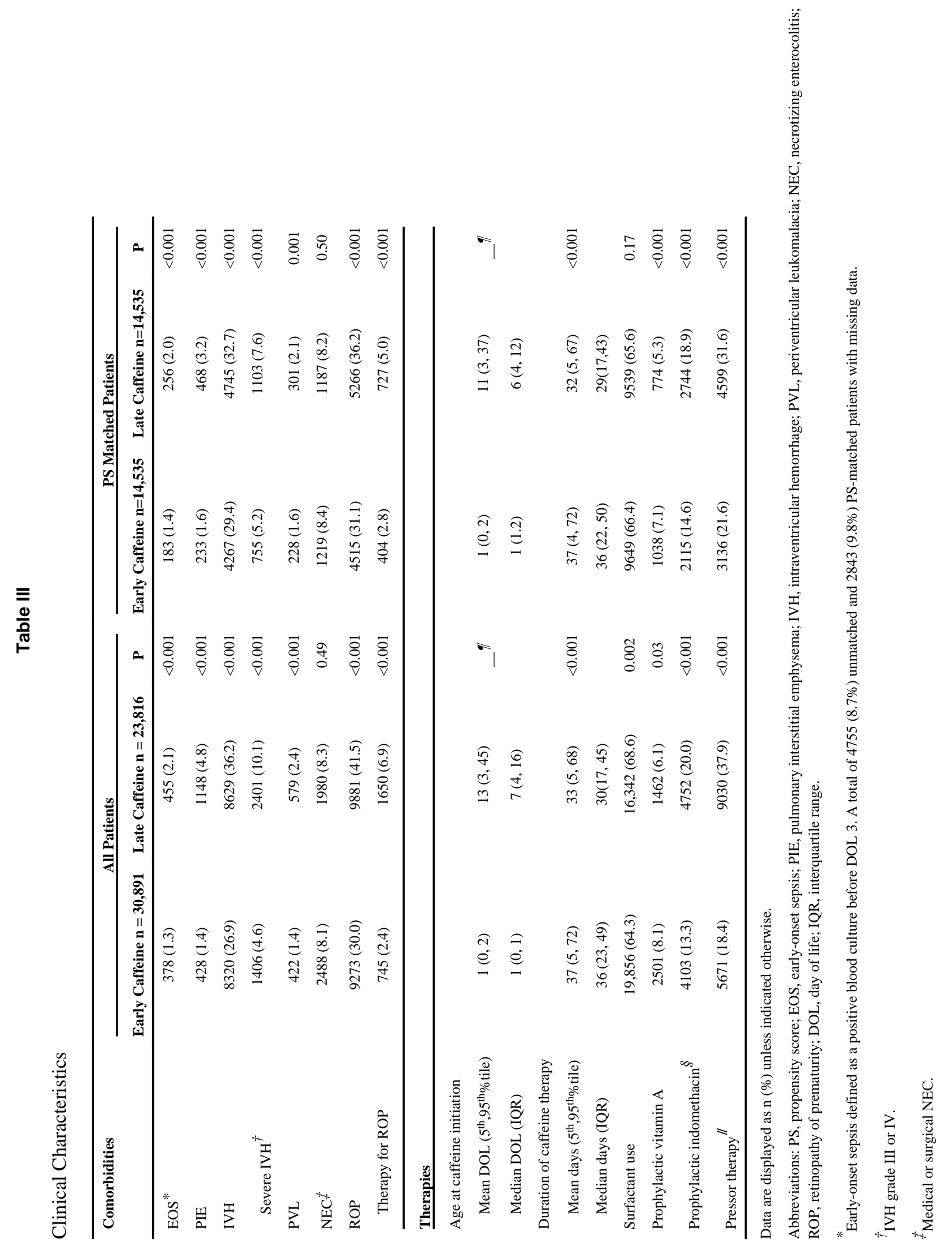




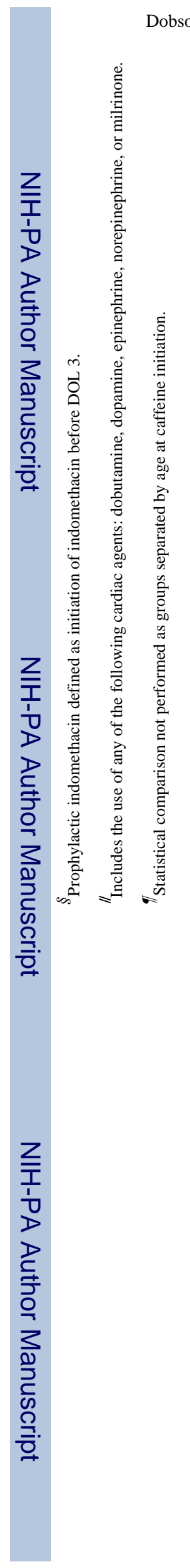

Page 21

J Pediatr. Author manuscript; available in PMC 2015 May 01. 


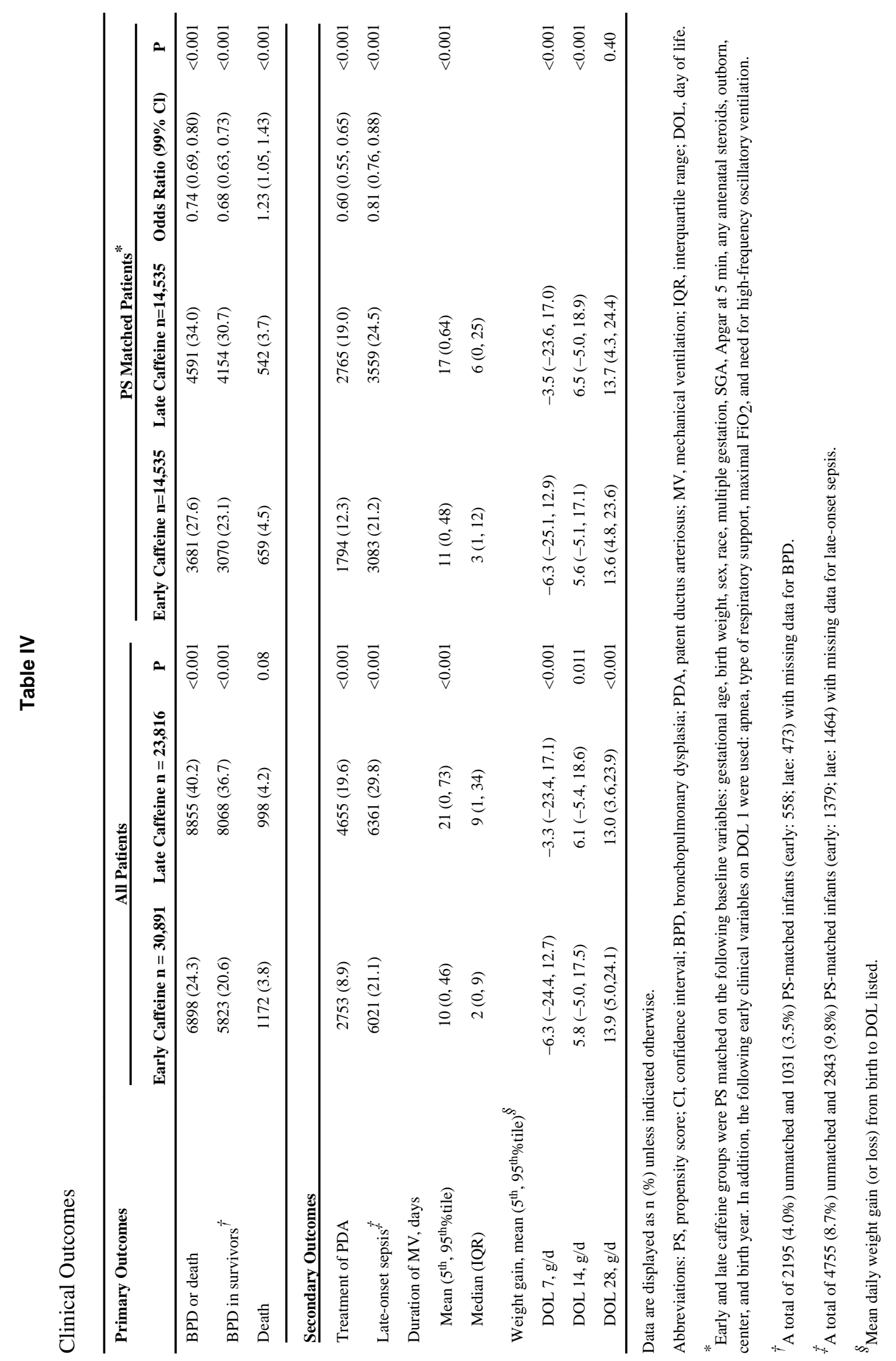


Table V

Primary Outcome by Gestational Age Subgroups (Online)

\begin{tabular}{|c|c|c|c|c|c|c|}
\hline \multirow[t]{2}{*}{ GA } & \multicolumn{3}{|c|}{ BPD in Survivors } & \multicolumn{3}{|c|}{ Death } \\
\hline & Early & Late & OR $(99 \% \mathrm{Cl})$ & Early & Late & OR $(99 \% \mathrm{CI})$ \\
\hline$<24$ week & $86(43.7)$ & $538(67.1)$ & $0.38(0.25,0.58)$ & $80(33.2)$ & $132(15.3)$ & $2.76(1.77,4.28)$ \\
\hline 24-28 week & $4346(29.0)$ & $5996(49.7)$ & $0.41(0.39,0.44)$ & $927(5.5)$ & $745(5.6)$ & $0.99(0.87,1.13)$ \\
\hline 29-32 week & $1274(10.9)$ & $1340(17.2)$ & $0.59(0.53,0.66)$ & $140(1.1)$ & $97(1.2)$ & $0.97(0.69,1.36)$ \\
\hline$>32$ week & $109(7.3)$ & $177(13.4)$ & $0.51(0.36,0.71)$ & $21(1.4)$ & $22(1.6)$ & $0.83(0.38,1.84)$ \\
\hline \multirow[t]{2}{*}{ GA } & \multicolumn{3}{|c|}{ BPD or Death } & & & \\
\hline & Early & Late & OR $(99 \% \mathrm{Cl})$ & & & \\
\hline$<24$ week & $163(82.7)$ & $645(80.4)$ & $1.17(0.68,2.08)$ & & & \\
\hline 24-28 week & $5205(34.8)$ & $6592(54.7)$ & $0.44(0.41,0.47)$ & & & \\
\hline 29-32 week & $1395(12)$ & $1412(18.1)$ & $0.62(0.55,0.68)$ & & & \\
\hline$>32$ week & $123(8.2)$ & $188(14.2)$ & $0.54(0.39,0.74)$ & & & \\
\hline
\end{tabular}

Abbreviations: GA, gestational age; BPD, bronchopulmonary dysplasia; Early, early caffeine therapy; Late, late caffeine therapy; OR, odds ratio; $\mathrm{Cl}$, confidence interval. 